\title{
Nutrition, Fats, Polyunsaturated
}

National Cancer Institute

\section{Source}

National Cancer Institute. Nutrition, Fats, Polyunsaturated. NCI Thesaurus. Code C16111.

Study of polyunsaturated fats in relation to cancer. 